\title{
TELEHEALTH IS FACE-TO-FACE SERVICE DELIVERY
}

\author{
JANA CASON, DHS, OTR/L, FAOTA \\ SPALDING UNIVERSITY, LOUISVILLE, KY, USA
}

\begin{abstract}
The Commentary contests the increasingly outdated and narrow use of the terminology 'face-to-face' (often abbreviated as F2F) to connote clinical interactions in which both the client and the practitioner are physically present in the same room or space. An expanded definition is necessary because when delivered synchronously via videoconferencing, telehealth also provides face-to-face services (i.e., the practitioner and the client view each other's faces). Terminology that uses face-toface to connote only in-person care is limiting and perpetuates language that is out of line with progressive US regulatory language and broad interpretation within existing regulatory language. It is this author's hope that this commentary will raise awareness of the important policy implications associated with this seemingly minor distinction in terminology and impact the lingering misapplication of the term, face-to-face.
\end{abstract}

Keywords: Telehealth, Face-to-Face, In-person

The Commentary contests the increasingly outdated and narrow use of the terminology 'face-to-face' (often abbreviated as F2F) to connote clinical interactions in which both the client and the practitioner are physically present in the same room or space. An expanded definition is necessary because when delivered synchronously via videoconferencing, telehealth also provides face-to-face services (i.e., the practitioner and the client view each other's faces). Terminology that uses face-to-face to connote only in-person care is limiting and perpetuates language that is out of line with progressive US regulatory language and broad interpretation within existing regulatory language. Therefore, the use of face-to-face should include telehealth applications (Cason, 2012).

\section{TELEHEALTH IS FACE-TO-FACE}

In his 2011 State of the Union Address, President Barak Obama described the use of telehealth as being face-to-face (Linkous, 2011). President Obama stated: "It's about a firefighter who can download the design of a burning building onto a handheld device; a student who can take classes with a digital textbook; or a patient who can have face-to-face video chats with her doctor" (Obama, 2011). Federal regulation supports the broad interpretation of faceto-face to include telehealth. For example, the Centers for Medicare \& Medicaid Services (CMS; n.d.) defines telemedicine (used interchangeably in this commentary with telehealth) as "a cost-effective alternative to the more traditional face-to-face way of providing medical care (e.g., face-to-face consultations or examinations between provider and patient) that states can choose to cover under Medicaid" (para 2). Furthermore, CMS endorsed the use of telehealth to meet the face-to-face provision for Medicaid home health services (CMS, 2016).

State regulation also uses the term face-to-face when referencing telehealth. For example, the Arkansas Medical Board define a "proper physician-patient relationship" to include "a face-to-face examination using real time audio and visual telemedicine technology that provides information at least equal to such information as would have been obtained by an in-person examination" (Arkansas Medical Board, Section 8A1B). States have been responsive to the Centers for Medicare \& Medicaid Services interpretation that telehealth services are face-to-face when delivered synchronously with audio and video. Several states have passed or introduced legislation expanding their definition of face-to-face services to include telehealth in regulatory language (lowa Department of Human Services, 2017; Kentucky Cabinet for Health and Human Services, 2016; Minnesota State Legislature, 2017a; 2017b).

\section{IN-PERSON VS. FACE-TO-FACE}

Arguably, the term face-to-face is commonly used in the literature and media when the intended meaning is 'inperson' care. This usage inherently implies that telehealth, via videoconferencing, is not face-to-face care.

Researchers and other stakeholders are therefore encouraged to shift their terminology and use the term inperson rather than face-to-face when describing a traditional, in-person model of care in which all parties are present within the same physical space. This shift will improve the consistency of prevailing terminology and better 
align with progressive telehealth policy and regulatory language.

It is this author's hope that this commentary will raise awareness of the important policy implications associated with this seemingly minor distinction in terminology and impact the lingering misapplication of the term, face-to-face.

\section{REFERENCES}

Arkansas Medical Board. (2016, August 23). An amendment to Regulation 2.8 governing physician/patient relationships. Retrieved from http://170.94.37.152/REGS/060.00.16-003F16840.pdf

Cason, J. (2012, May 21). An introduction to telehealth as a service delivery model in occupational therapy [Continuing Educational Article]. OT Practice, 17(7), CE1-8.

Centers for Medicare \& Medicaid Services. (n.d.). Telemedicine. Retrieved from https://www.medicaid. gov/medicaid/benefits/telemed/index.htm

Centers for Medicare \& Medicaid Services. (2016, February 2). Medicaid program; face-to-face requirements for home health services; policy changes and clarifications related to home health. Retrieved from https://s3.amazonaws.com/publicinspection.federalregister.gov/2016-01585.pdf lowa Department of Human Services. (2017, May 10). Chapter 24. Accreditation of providers of services to persons with mental illness, intellectual disabilities, or developmental disabilities. Retrieved from https://www.legis.iowa.gov/docs/ACO/chapter/441.24.pdf

Kentucky Cabinet for Health and Human Services. (2016, July 7). 907 KAR 1:044. Coverage provisions and requirements regarding community mental health center behavioral health services. Retrieved from http://www.Irc.ky.gov/kar/907/001/044.htm

Linkous, J. (2011). Thank you Mr. President. Retrieved from https://thesource.americantelemed.org/blogs/jonathanlinkous/2011/01/26/thank-you-mr-president

Minnesota State Legislature. (2017, February 6). HF 887. Retrieved from https://www.revisor.mn.gov/bills/text.php?number=HF887\&ver sion $=0 \&$ session $=I$ s $90 \&$ session year $=2017 \&$ session number $=$ $\underline{0}$

Minnesota State Legislature. (2017, February 9). SF 781. Retrieved from https://www.revisor.mn.gov/bills/bill.php?f=SF781\&b=senate\&y $=2017 \&$ ssn $=0$

Obama, B. (2011). State of the Union 2011. Retrieved from http://abcnews.go.com/Politics/State of the Union/state-ofthe-union-2011-full-transcript/story?id=12759395
This work is licensed under a Creative Commons Attribution 4.0 International License.

This journal is published by the University Library System of the University of Pittsburgh as part of its D-Scribe Digital Publishing Program and is cosponsored by the University of Pittsburgh Press. 